\title{
Mental disorders and quality of life in COPD patients and their spouses
}

\author{
Kerstin Kühl' \\ Wolfgang Schürmann ${ }^{2}$ \\ Winfried Rief ${ }^{\prime}$ \\ 'Philipps University Marburg, \\ Department of Psychology, Clinical \\ Psychology and Psychotherapy, \\ Gutenbergstraße 18, D - 35032 \\ Marburg, Germany; ${ }^{2}$ Private \\ pulmonary practice, Bahnhofstraße 30 , \\ D - 35037 Marburg, Germany
}

Correspondence: Kerstin Kühl

Philipps University Marburg,

Department of Psychology, Clinical

Psychology and Psychotherapy,

Gutenbergstraße I8, D - 35032 Marburg,

Germany

Tel +642I 28283657

Fax +642I 2828904

Email kuehl@staff.uni-marburg.de

\begin{abstract}
In the current study, the prevalence of the most common psychological disorders in COPD patients and their spouses was assessed cross-sectionally. The influence of COPD patients' and their spouses' psychopathology on patient health-related quality of life was also examined. The following measurements were employed: Forced expiratory volume in 1 second expressed in percentage predicted $\left(\mathrm{FEV}_{1} \%\right.$ ), Shuttle-Walking-Test (SWT), International Diagnostic Checklists for ICD-10 (IDCL), questionnaires on generic and disease-specific healthrelated quality of life (St. George's Respiratory Questionnaire (SGRQ), European Quality of Life Questionnaire (EuroQol), a modified version of a Disability-Index (CDI)), and a screening questionnaire for a broad range of psychological problems and symptoms of psychopathology (Symptom-Checklist-90-R (SCL-90-R)). One hundred and forty-three stable COPD outpatients with a severity grade between 2 and 4 (according to the GOLD criteria) as well as 105 spouses took part in the study. The prevalence of anxiety and depression diagnoses was increased both in COPD patients and their spouses. In contrast, substance-related disorders were explicitly more frequent in COPD patients. Multiple linear regression analyses indicated that depression (SCL-90-R), walking distance (SWT), somatization (SCL-90-R), male gender, $\mathrm{FEV}_{1} \%$, and heart disease were independent predictors of COPD patients' health-related quality of life. After including anxiousness of the spouses in the regression, medical variables $\left(\mathrm{FEV}_{1} \%\right.$ and heart disease) no longer explained disability, thus highlighting the relevance of spouses' well-being. The results underline the importance of depression and anxiousness for health-related quality of life in COPD patients and their spouses. Of special interest is the fact that the relation between emotional distress and quality of life is interactive within a couple.
\end{abstract}

Keywords: COPD, quality of life, anxiety, depression, disability, spouses

\section{Introduction}

Comorbid symptoms of anxiety and depression are common in patients with chronic obstructive pulmonary disease (COPD) (Yohannes et al 2006) and cause a number of negative effects. Compared with non-depressed COPD patients, COPD patients with elevated depression scores show lower health-related quality of life (Mikkelsen et al 2004; Yohannes et al 2006; Ng et al 2007), a lower level of functioning (Kim et al 2000), longer and more frequent hospital stays ( $\mathrm{Ng}$ et al 2007), and increased mortality, as shown in prospective studies (Crockett et al 2002; Ng et al 2007). Similarly, increased levels of anxiety lead to impairment of quality of life (Kim et al 2000; Di Marco et al 2006) and more frequent hospital admissions in COPD patients (Gudmundsson et al 2005; Yohannes et al 2005). However, the reported prevalence rates for comorbid symptoms of depression or anxiety are highly variable: in studies using anxiety and depression self-report questionnaires, these rates range from 13\% and 7\% (Engström et al 2001) to $96 \%$ and $79 \%$, respectively (Borak et al 1991; Hynninen et al 2005). The few studies that assessed categorical diagnoses by means of international diagnosis systems such as the ICD-10 (WHO 1993) or the DSM-III-R/-IV (Saß et al 1996) also 
reported inconsistent but lower prevalence rates, ranging from $10 \%$ to $35 \%$ and $16 \%$ to $47 \%$, respectively (Yellowlees et al 1987; Karajgi et al 1990; Aghanwa and Erhabor 2001; Aydin and Ulusahin 2001; Stage et al 2003). However, the generalization of these results is limited by the small sample sizes and the absence of control groups.

The inconsistency of previous findings may partly be due to varying inclusion criteria (eg, COPD grade $1-4$, outpatients versus in-patients, stable or with exacerbation, with or without oxygen therapy) research strategies, and employed instruments. The use of screening questions that are highly sensitive to detect symptoms of anxiousness and dysphoria generally result in an extremely high proportion of individuals screened positive (Kunik et al 2005). In contrast, self-report questionnaires assessing levels of symptomatology result in a smaller proportion of potentially disordered individuals. The presence of a clinically significant mental disorder, however, can be determined only on the basis of categorical diagnostics according to international classification systems such as the ICD-10 (WHO 1993). These diagnoses are based on a defined set of symptom criteria. Precise case definition criteria for each symptom (severity, frequency, duration) as well as explicit inclusion and exclusion criteria usually result in high inter-rater reliabilities. Thus, categorical diagnostics can be considered the gold standard in diagnosing mental disorders. Overall, though, few studies have employed such elaborate classification systems of mental disorders, and even fewer have compared their results with those of control groups (eg, Aghanwa and Erhabor 2001; Lin et al 2005).

It is well documented that spouses of patients with other severe and life-threatening somatic diseases may encounter comparable psychosocial and emotional distress as the patients themselves. However, very few COPD studies have addressed this issue (Kim et al 2000; Kanervisto et al 2007; Pinto et al 2007). In two studies, the spouses of COPD patients reported levels of loneliness and depressive mood comparable to the levels reported by the patients themselves (Keele-Card et al 1993; Kara et al 2004). To our knowledge, there have been no studies on the prevalence of mental disorders in spouses of COPD patients, even though their state of health may be of particular importance for the supportive care of patients.

The first purpose of the present study was to compare the prevalence of mental disorders in COPD patients with the prevalence in two reference groups of elderly persons. The second purpose was to investigate the prevalence of mental disorders in the spouses. Specifically, we examined the following questions: (1) Does the psychopathology of the patients and that of their spouses correlate with the health-related quality of life of the patients? (2) How is the COPD-related disability of spouses related to clinical variables of patients?

\section{Methods}

\section{Measures}

First, a bodyplethysmography (MasterScreenBody by Viasys/ Jaeger) was performed, in accordance with the American Thoracic Society guidelines, as well as a shuttle walking test (Singh et al 1992; Dyer et al 2002). The subjects performed only one test at baseline. Three to 10 days later, psychological diagnostics were carried out in the homes of the COPD patients by a clinical psychologist (Kerstin Kühl), who was blind to the results of lung function testing. At the beginning of the home assessment, patients and their spouses underwent a screening interview to assess for the presence of cardinal symptoms of depressive disorders (ICD-10 diagnosis of depressive episode [F32] or recurrent depressive disorder [F33]), dysthymia, panic disorder, agoraphobia, generalized anxiety disorder, as well as nicotine and alcohol abuse. For participants screened positive, categorical diagnostics (International Diagnostic Checklists for ICD-10) (Hiller et al 1997) were used. Subsequently, the following questionnaires were applied:

\section{The St. Georges Respiratory Questionnaire (SGRQ)} (German version: Hütter 2003)

The SGRQ assesses the subjective quality of life of COPD patients. Thus it cannot be rated by the spouses.

\section{COPD Disability Index (CDI)}

In contrast, COPD-related disability assessing reductions of social functioning and self-care can be rated both by patients and their spouses. The CDI is an adaptation of the Pain Disability Index (PDI) (Dillmann et al 1994). The original version comprises 7 items: family/home, responsibilities, recreation, social activity, occupation, sexual behavior, self-care, and life-support activities (breathing, sleeping, eating). For the purpose of the present study, item 7 (breathing, sleeping, eating) was limited to breathing. Since COPD is a respiratory disease, breathing, eating, and sleeping are affected differently and thus cannot be averaged in this study population. The degree of disability caused by the disease is rated on an 11-point rating scale for all respective aspects of life. In general, factor analyses with different patient groups and with spouses of pain patients 
have yielded one factor and confirmed the unidimensionality of the construct (Dillmann et al 1994), although there have been two exceptions (Tait et al 1987; Tait and Chibnall 2005). Spouses were instructed to evaluate their perceived disability due to their partner's illness.

\section{The European Quality of Life Questionnaire (EuroQol) (Schulenburg et al 1998)}

The EuroQol assesses the generic health-related quality of life by means of a visual analogue scale. The scale ranges from 0 ("the worst state of health to be imagined") to 100 ("the best state of health to be imagined").

\section{The Symptom-Checklist-90-R (SCL-90-R) (Franke 2000)}

The SCL-90-R assesses physical and psychological symptoms within the last week. Only subscales that are relevant for the issue under investigation (depression, anxiousness, phobic anxiety, somatization) were included in the analysis. Two items of the somatization scale (chest pain and breathing difficulties) were excluded, since these symptoms might reflect actual symptoms of COPD rather than symptoms of psychopathology.

\section{Statistical analysis}

The data was analysed using SPSS (v. 15.0. SPSS Inc., Chicago, IL). Internal consistency for the modified COPD-Disability-Index (CDI) was determined using Cronbach's alpha. Of particular note was the high internal consistency in the CDI (P-CDI $=0.92$; S-CDI (without item 7 breathing $)=0.86)($ For reasons of clarity, variables assessed on COPD patients and their spouses will be labeled with P [for COPD patients' data] and S [for spouses' data].)The significant Pearson correlations between COPD-related disability (P-CDI) and the SGRQ in patients (SGRQ-S $\mathrm{r}=0.59$; SGRQ-A $\mathrm{r}=0.74$; SGRQ-I $\mathrm{r}=0.81$; SGRQ-T $r=0.83$; all $p<0.01$ ) support the convergent validity of this new instrument. In addition, the significant associations between COPD-related disability in the spouses (S-CDI) and the SGRQ in the patients (SGRQ-S $r=0.35$; SGRQ-A $r=0.45$; SGRQ-I $r=0.59$; SGRQ-T $r=0.56$; all $p<0.01$ ) not only highlight the relationship between patient's health and partner's disability, but confirm that the CDI is a very short but nonetheless reliable and valid instrument.

The results of our patient and spouse samples will be compared with normative data of two representative samples of elderly persons (Wernicke et al 2000;
Trollor et al 2007). Comparisons for patients with and without mental disorders were computed by means of t-tests for independent samples and chi square tests. For nonparametrical variables Mann-Whitney U-test were analysed. Recent research (eg, Chavannes et al 2005; Cully et al 2006; Di Marco et al 2006; Ng et al 2007) has highlighted nine variables $\left(\mathrm{FEV}_{1}\right.$, walking distance, gender, heart disease, somatization, anxiousness, depression (SCL-90-R), phobic anxiety (SCL-90-R), depression/anxiety diagnoses) as relevant predictors of health-related quality of life in patients with COPD. These variables were included in a stepwise multiple linear regression to predict patients' health-related quality of life (SGRQ). Furthermore, the part of explained variance of the COPD-related disability of the spouses (S-CDI) was calculated.

\section{Patient sample}

Over a period of 9 months, all COPD patients of a private pulmonary practice were consecutively asked if they wanted to take part in the study. Patients with a severity grade of 2 , 3 , or 4 (according to the GOLD criteria) who had been at the routine appointment 3 respectively 6 months before were included. All participants received $€ 10$ and a small present (candy) as reimbursement for their participation. Exclusion criteria were, for patients, illness exacerbation within the previous month or, for patients and spouses, a severe acute illness (such as myocardial infarction, tumor) within the last year. Of the 165 COPD patients who were approached, only $15(9.1 \%)$ declined to participate. Ten participants -7 patients $(4.2 \%)$ and 3 spouses $(2.7 \%)$ - had to be excluded for reasons of illness exacerbation (2), diagnosis of tumor (3), psychosis (1), missing data (1), possible dementia (2), or insufficient language abilities (1). Another couple was excluded from the comparison of couples because both were COPD patients. Thus, 143 COPD patients (and 105 spouses) were included in the analysis. The duration of illness was less than one year in $4.6 \%$ of patients, $1-3$ years in $12.8 \%$ of patients, $3-10$ years in $12.8 \%$ of patients, and more than 10 years in $50.5 \%$ of patients. Within 12 months prior to the study, 15 patients $(10.5 \%)$ had been admitted to hospital due to COPD exacerbation and two (1.4\%) to a comprehensive pulmonary rehabilitation.

\section{Results}

\section{Comorbid mental disorders}

Most of the 143 COPD patients ( $80.4 \% / 75.2 \%$ of the spouses) did not fulfil the criteria of any of the investigated depressive or anxiety disorders (Table 2). 
Table I Sample characteristics

\begin{tabular}{|c|c|c|c|c|}
\hline & Patients $(n=143)$ & & & Spouses $(n=105)$ \\
\hline Age (years) & $67.0 \pm 9.5$ range: $40-90$ & & & $64.0 \pm 9.3$ range: $43-84$ \\
\hline Gender (F:M) & $3 \mathrm{I}: 1 \mid 2$ (2।.7 : 78.3\%) & & & $19: 86$ (81.9 : I8.1\%) \\
\hline \multicolumn{5}{|l|}{ Marital status } \\
\hline Single & $8(5.5 \%)$ & & & \\
\hline Separated & II (7.7\%) & & & \\
\hline Widowed & $14(9.8 \%)$ & & & \\
\hline Married & 110 (76.9\%) & & & $105(100 \%)$ \\
\hline \multicolumn{5}{|c|}{ Years of marriage $37.8 \pm 12.8$ range: $4-66$} \\
\hline \multicolumn{5}{|l|}{ Education } \\
\hline$\leq 9$ years & 110 (76.9\%) & & & $86(80.1 \%)$ \\
\hline 10 years & 19 (I3.3\%) & & & $14(9.8 \%)$ \\
\hline 13 years & $14(9.8 \%)$ & & & $5(3.5 \%)$ \\
\hline COPD severity & $\mathrm{FEV}, \%$ pred & SWT & Comorbid heart disease & \\
\hline $2 n=68(47.6 \%)$ & $62.9 \pm 9.6$ & $402 \pm 24 I$ & $\mathrm{n}=30(44.1 \%)$ & \\
\hline $3 n=62(43.4 \%)$ & $40.8 \pm 5.3$ & $219 \pm 161$ & $\mathrm{n}=28(45.2 \%)$ & \\
\hline $4 n=13(9.1 \%)$ & $26.4 \pm 2.8$ & $118 \pm 133$ & $\mathrm{n}=5(38.5 \%)$ & \\
\hline
\end{tabular}

Data presented as $\mathrm{n}$, mean $\pm \mathrm{SD}$

Abbreviations: $\mathrm{FEV}, \%$ pred, forced expiratory volume in I second expressed in percentage predicted; SWT, shuttle walking test (in meters); comorbid heart disease, coronary heart disease, myocardial infarction or cardiac failure.

COPD patients and their spouses were compared with a representative German aging study, which also used categorical diagnoses (Wernicke et al 2000). The prevalence rates for anxiety and depressive disorders (except for dysthymia) were higher than in the reference sample for both patients and their spouses (see Table 2). Only five out of these 29 patients were taking psychotropic medication and no patients were receiving any form of psychological support or psychotherapeutic treatment. The prevalence of anxiety or depressive disorders was not influenced by COPD severity (grade $2=23.6 \%$; grade $3=26.5 \%$; grade $4=18.2 \% ; \chi^{2}=0.23, \mathrm{df}=2, \mathrm{p}=$ n.s.). In the present study, $7.7 \%$ of COPD patients met criteria for alcohol abuse and/or dependence. Although this rate was lower than reported by Stage et al (2003), it was significantly higher compared with two reference samples (Wernicke et al 2000; Trollor et al 2007).

As expected, only $4.9 \%$ of the patients had always been non-smokers, compared with $61.9 \%$ of the spouses. This difference is significant and cannot be explained by gender differences (females, Pearson's $\chi^{2}=51.26, \mathrm{df}=2, \mathrm{p}<0.001$; males, Pearson's $\chi^{2}=14.40, \mathrm{df}=2, \mathrm{p}<0.001$ ). The percentage of participants with clinically relevant SCL-90-R T-scores (ie, those with scores $\geq$ mean $+1 \mathrm{SD}$ ) was significantly higher in patients compared to spouses: somatization, $39.2 \%$ (vs $21.9 \%$,
Pearson's $\chi^{2}=8.31, \mathrm{df}=1, \mathrm{p}<0.004$ ), depression (SCL-90-R), $29.4 \%$ (vs 16.2\%, Pearson's $\chi^{2}=5.80, \mathrm{df}=1, \mathrm{p}<0.016$ ), anxiousness, $25.2 \%$ (vs 15.2\%, Pearson's $\chi^{2}=3.61, \mathrm{df}=1, \mathrm{p}$ $<0.057$ ), and phobic anxiety (SCL-90-R), 18.2\% (vs 5.7\%, Pearson's $\left.\chi^{2}=8.37, \mathrm{df}=1, \mathrm{p}<0.004\right)$. There was a low but significant positive correlation between self-reported duration of illness and all SCL-90-R subscales - even after controlling for age and $\mathrm{FEV}_{1} \%$ (partial correlation: somatization $\mathrm{r}_{\mathrm{p}}=0.24$, depression $r_{p}=0.24$, anxiousness $r_{p}=0.20$, phobic anxiety $r_{p}=0.22 ;$ all $\left.p<0.05\right)$.

\section{Quality of Life}

It is important to note that the quality of life was considerably lower compared to the general 1 (EuroQol: $\mathrm{CI}=76.3-77.1-77.9)$ in both patients (EuroQol: $\mathrm{CI}=46.6-50.2-53.9$ ) and spouses (EuroQol: $\mathrm{CI}=62.6-66.5-$ 70.5). COPD patients with mental disorders reported significantly higher scores on subscales for psychosocial impact (SGRQ-I) and health related quality of life (SGRQ-T) than patients without mental disorders (see Table 3). There was no difference between COPD patients with and without mental disorders with regard to sociodemographic variables (age, gender), restriction of lung functioning $\left(\mathrm{FEV}_{1} \%\right)$, walking distance, or general healthrelated quality of life (EuroQol). 
Table 2 Comorbid mental disorders in COPD patients and their spouses

\begin{tabular}{|c|c|c|c|c|c|c|}
\hline & \multirow[b]{2}{*}{$\begin{array}{l}\text { Patients } \\
(n=143)\end{array}$} & \multicolumn{2}{|c|}{2 representative samples } & \multirow[b]{2}{*}{$\begin{array}{l}\text { Spouses } \\
(n=105)\end{array}$} & \multicolumn{2}{|c|}{ Significance Pearson's $\chi^{2}$} \\
\hline & & $\begin{array}{l}\text { BASE } \\
(n=5 \mid 6)\end{array}$ & $\begin{array}{l}\text { NMHWS } \\
(n=1792)\end{array}$ & & $\begin{array}{l}\text { BASE/ } \\
\text { Patients }\end{array}$ & $\begin{array}{l}\text { BASE/ } \\
\text { Spouses }\end{array}$ \\
\hline \multicolumn{7}{|l|}{ Anxiety/depression diagnoses: } \\
\hline Depressive disorder & $17(11.9 \%)$ & $4.8 \%$ & $1.1 \%$ & $18(17.1 \%)$ & $\mathrm{p}<.003$ & $\mathrm{P}<.00 \mathrm{I}$ \\
\hline Dysthymia & $3(2.1 \%)$ & $2.0 \%$ & $0.1 \%$ & $4(2.8 \%)$ & n.s. & n.s. \\
\hline Panic disorder and/or agoraphobia & II (7.7 \%) & $0.8 \%$ & $0.5 \%$ & $5(4.8 \%)$ & $\mathrm{p}<.00 \mathrm{I}$ & $\mathrm{P}<.001$ \\
\hline Generalized anxiety disorder & $8(5.6 \%)$ & $0.9 \%$ & $1.7 \%$ & 7 (6.7 \%) & $\mathrm{P}<.00 \mathrm{I}$ & $\mathrm{P}<.001$ \\
\hline \multicolumn{7}{|l|}{ Alcohol dependence or harmful use: } \\
\hline At present & II (7.7 \%) & $1.2 \%$ & $0.3 \%$ & I (I.0\%) & $\mathrm{P}<.00 \mathrm{I}$ & n.s. \\
\hline Lifetime & 14 (9.8 \%) & & & $2(2.0 \%)$ & & \\
\hline Non-existent & I I 8 (82.5 \%) & & & $102(97.1 \%)$ & & \\
\hline \multicolumn{7}{|l|}{ Nicotine dependence or abuse: } \\
\hline At present & $31(21.7 \%)$ & \multirow{2}{*}{\multicolumn{2}{|c|}{ not assessed }} & $23(21.9 \%)$ & & \\
\hline Former smoker & 105 (73.4 \%) & & & $17(16.2 \%)$ & & \\
\hline Non-smoker & 7 (4.9\%) & & & $65(61.9 \%)$ & & \\
\hline
\end{tabular}

Abbreviations: BASE, German Aging Study (data are DSM-III-R diagnoses according to Wernicke et al 2000); NMHWS, national mental health and well-being-survey (data according to Trollor et al 2007).

The nine variables $\left(\mathrm{FEV}_{1}\right.$, walking distance, gender, heart disease, somatization, anxiousness, depression (SCL-90-R), phobic anxiety (SCL-90-R), depression/ anxiety diagnoses), which had previously been identified as relevant predictors of health-related quality of life in patients with COPD, were included in a multiple regression model to predict health-related quality of life (SGRQ-T; Table 4).

The present study identified 6 variables (Table 4, model $A$, adjusted $\left.R^{2}=0.64, p<0.001\right)$ as significant predictors of health-related quality of life. In a second regression analysis, spouse variables were included in addition to the above listed patient variables (model $\mathrm{B}$, adjusted $\mathrm{R}^{2}=0.62, \mathrm{p}<0.001$ ). The greatest proportion of variance in both models was explained by the patients' depression scores (SCL-90-R), walking distance (SWT), somatization, and male gender. In model B, spouses' anxiousness was a significant predictor of patients' health related quality of life, while the objective measures $\mathrm{FEV}_{1} \%$ and heart disease were not found to be significant predictors.

In addition, we analyzed whether the predictor variables from the first regression analysis (model A) would also predict spouses' perceived disability due to their partners' illness (criterion: S-CDI) (Table 4). Twenty-seven percent of the variance (model $\mathrm{C}$, adjusted $\mathrm{R}^{2}=0.27, \mathrm{p}<0.001$ ) of the $\mathrm{S}-\mathrm{CDI}$ was explained by the patient variables somatization, walking distance (SWT), and depression (SCL-90-R), again confirming the close relationship of the partner's well-being with patients' health.

In the fourth regression analysis psychosocial impact of the COPD patients in the SGRQ and the extent of other physical symptoms (P-somatization) predicted COPD-related disability in the spouses (model $\mathrm{D}$, adjusted $\mathrm{R}^{2}: 0.36, \mathrm{p}<0.001$ ).

\section{Discussion}

The present study investigated the prevalence of mental disorders and quality of life in 143 consecutive COPD patients attending a private pulmonary practice as well as 105 spouses.

1. Results revealed significantly increased prevalence rates for depressive disorders, anxiety disorders, and alcohol related disorders in COPD patients compared to a representative German reference sample (Wernicke et al 2000) and a German aging study (DHS 2005). Similarly, increased prevalence rates for depressive and anxiety disorders were found in patients' spouses.

The high rates of alcohol abuse and dependence in patients in this study might be a result of more genuine response tendencies: during the screening of substancerelated disorders - and only at this point - some of the spouses intervened and urged their partners to be more honest about the amount of alcohol consumption (Stage et al 2003). 
2. The second aim of this study was to investigate predictors of quality of life in COPD patients and their spouses. Results identified 6 out of 9 theoretically derived variables (somatization, depression [SCL-90-R], walking distance $[\mathrm{SWT}]$, gender, $\mathrm{FEV}_{1} \%$, heart disease) as significant predictors of health-related quality of life in COPD patients. When including spouse variables, the objective variables ( $\mathrm{FEV}_{1} \%$, heart disease) failed to remain significant predictors for patients' quality of life, while symptoms of anxiousness in spouses explained substantial variance. This emphasizes the importance of spouses' anxiousness for the health-related quality of life in the patients.

3. On the other hand, $36 \%$ of the total variance in spouses' COPD-related disability could be explained by disease-specific psychosocial impact (SGRQ-I) and the physical condition of the patients (somatization). This is a further indication that spouses of COPD patients are substantially affected by the disease of their partners, a fact that previous studies have already highlighted (Keele-Card et al 1993; Kara et al 2004; Kanervisto et al 2007; Pinto et al 2007).

\section{Limitations}

Our study has several limitations. First, despite a comprehensive psycho-diagnostic assessment, the number of investigated diagnoses was limited in the present study. Second, some diagnostic criteria were difficult to evaluate in this patient group. For example, in order to receive a diagnosis of panic disorder, symptoms must not be due to a medical condition. In the case of patients with comorbid heart disease or severe dyspnea this is difficult to decide. Third, the cross-sectional design of this study does not allow conclusions to be drawn about the causal relationship between COPD, psychological disorders, and quality of life in the patients or psychological diagnoses and quality of life in the spouses. Furthermore, no conclusions can be drawn about the causal relation between patient variables and psychological disorders or quality of life in their spouses. Fourth, patients included in this study were stable out-patients at a private pulmonary practice. The present results may thus not be generalized to hospitalized patients or patients with acute exacerbation.

\section{Implications \\ Diagnostic}

The extensive diagnostic assessment according to ICD-10 was only conducted with respect to diagnoses which have frequently been investigated in COPD patients. It is likely that alcohol dependency is a comorbid disorder which so far has not received enough attention.

It is important to point out that a considerate number of patients who did not fulfil criteria for a current diagnosis reported having experienced severe symptoms of depression or anxiety on a few days in the past year (often during periods of COPD exacerbation). However, if a patient fulfils

Table 3 Comparison of means in COPD patients with and without mental disorders

\begin{tabular}{|c|c|c|c|c|c|c|c|}
\hline & \multicolumn{2}{|c|}{$\begin{array}{l}\text { Patients with mental } \\
\text { disorder }(n=28)\end{array}$} & \multicolumn{2}{|c|}{$\begin{array}{l}\text { Patients without mental } \\
\text { disorder }(n=115)\end{array}$} & \multirow[b]{2}{*}{ test statistics } & \multirow[b]{2}{*}{ df } & \multirow[b]{2}{*}{ Sig. I-sided } \\
\hline & $M$ & SD & $M$ & SD & & & \\
\hline Gender $^{\mathrm{a}}(\mathrm{F}: \mathrm{M})$ & \multicolumn{2}{|c|}{$8: 20$} & \multicolumn{2}{|c|}{$23: 90$} & & & n.s \\
\hline Age (years) & 67.0 & 9.6 & 64.0 & 9.3 & & & n.s. \\
\hline SWT & 298 & 221 & 297 & 227 & & & n.s. \\
\hline $\mathrm{FEV}_{1} \%$ pred & 50.3 & 15.6 & 50.0 & 14.8 & & & n.s. \\
\hline \multicolumn{8}{|l|}{ SGRQ } \\
\hline Symptoms & 57.7 & 25.1 & 63.8 & 22.9 & & & n.s. \\
\hline Activities & 65.2 & 25.6 & 60.0 & 22.6 & & & n.s. \\
\hline Impact & 64.9 & 37.1 & 49.1 & 30.1 & -2.37 & $|4|$ & 0.010 \\
\hline Total score & 64.8 & 29.1 & 53.8 & 24.6 & -2.04 & $14 \mid$ & 0.022 \\
\hline EuroQol $^{\mathrm{b}}$ & 43.9 & 29.5 & 51.8 & 19.9 & & & n.s. \\
\hline CDI & 5.27 & 2.83 & 4.25 & 2.86 & & & n.s. \\
\hline
\end{tabular}

Test statistics are t-tests, if not otherwise specified.

${ }^{a} \chi^{2}$; bMann-Whitney U-Score.

Abbreviations: SWT, shuttle walking test; FEV,\% pred, forced expiratory volume in I second expressed in percentage predicted; SGRQ, st. george's respiratory questionnaire; EuroQol, european quality of life questionnaire; CDI, COPD-disability-index. 
Table 4 Stepwise multiple linear regressions

\begin{tabular}{|c|c|c|c|c|c|}
\hline \multicolumn{6}{|c|}{ criterion: health-related quality of life in patients (SGRQ-T) } \\
\hline \multicolumn{3}{|c|}{ Model A: only patient variables } & \multicolumn{3}{|c|}{ Model B: patient and spouse variables } \\
\hline Significant Predictors: & $\beta$ & $P$ & Significant Predictors: & $\beta$ & $P$ \\
\hline $\begin{array}{l}\text { P-Depression } \\
\text { (SCL-90-R) }\end{array}$ & 0.32 & $<0.001$ & $\begin{array}{l}\text { P-Somatization } \\
\text { (SCL-90-R) }\end{array}$ & 0.22 & 0.015 \\
\hline $\begin{array}{l}\text { Walking distance } \\
\text { (SWT) }\end{array}$ & -0.36 & $<0.001$ & $\begin{array}{l}\text { Walking distance } \\
(\text { SWT) }\end{array}$ & -0.53 & $<0.001$ \\
\hline $\begin{array}{l}\text { P-Somatization } \\
(\mathrm{SCL}-90-\mathrm{R})\end{array}$ & 0.27 & $<0.001$ & $\begin{array}{l}\text { P-Depression } \\
\text { (SCL-90-R) }\end{array}$ & 0.30 & $<0.001$ \\
\hline $\begin{array}{l}\text { P-Gender } \\
(\mathrm{I}=\mathrm{F} ; 2=\mathrm{M})\end{array}$ & 0.14 & 0.009 & $\begin{array}{l}\text { S-Anxiousness } \\
(\mathrm{SCL}-90-\mathrm{R})\end{array}$ & 0.16 & 0.024 \\
\hline $\mathrm{FEV}, \%$ pred & -0.15 & 0.014 & $\begin{array}{l}\text { P-Gender } \\
(\mathrm{I}=\mathrm{F} ; 2=\mathrm{M})\end{array}$ & 0.14 & 0.028 \\
\hline Heart disease & 0.13 & 0.027 & & & \\
\hline $\begin{array}{l}\text { Excluded variables: } \\
\text { SCL-90-R: P-Anxiousne } \\
\text { diagnoses }\end{array}$ & ic anxie & ssion/anxiety & $\begin{array}{l}\text { Excluded variables: } \\
\text { FEV } \% \text { pred; heart diseas } \\
\text { S-Depression, S-Phobic a }\end{array}$ & r; & atization, \\
\hline \multicolumn{6}{|c|}{ criterion: COPD-related disability in spouses (S-CDI) } \\
\hline \multicolumn{3}{|c|}{ Model C: patient variables from model A } & \multicolumn{3}{|c|}{$\begin{array}{l}\text { Model D: patient variables from model C plus SGRQ } \\
\text { scores }\end{array}$} \\
\hline Significant Predictors: & $\beta$ & $P$ & Significant Predictors: & $\beta$ & $P$ \\
\hline $\begin{array}{l}\text { P-Somatization }{ }^{\mathrm{a}} \\
\text { (SCL-90-R) }\end{array}$ & 0.24 & 0.057 & $\begin{array}{l}\text { Impact } \\
(\text { SGRQ) }\end{array}$ & 0.46 & $<0.001$ \\
\hline $\begin{array}{l}\text { Walking distance } \\
\text { (SWT) }\end{array}$ & -0.36 & 0.016 & $\begin{array}{l}\text { P-Somatization } \\
\text { (SCL-90-R) }\end{array}$ & 0.22 & 0.024 \\
\hline $\begin{array}{l}\text { P-Depression } \\
(\mathrm{SCL}-90-\mathrm{R})\end{array}$ & 0.27 & 0.020 & & & \\
\hline \multirow{2}{*}{\multicolumn{3}{|c|}{$\begin{array}{l}\text { Excluded variables: } \\
\text { SCL-90-R: P-Anxiousness, P-Phobic anxiety; P-Gender; P-depression/ } \\
\text { anxiety diagnoses; FEV, pred; heart disease }\end{array}$}} & \multicolumn{3}{|l|}{ Excluded variables: } \\
\hline & & & \multicolumn{3}{|c|}{$\begin{array}{l}\text { SCL-90-R: P-Depression;Walking distance (SWT); FEV,\% pred; } \\
\text { heart disease; P-Gender; SGRQ: symptoms, activities; S-Gender }\end{array}$} \\
\hline
\end{tabular}

st. george's respiratory questionnaire; $\mathrm{P}-\ldots$... patient variables; $\mathrm{S}-. . .$, spouse variables.

all symptoms necessary for a diagnosis of depression for only 9 days, a diagnosis of depression (ICD-10 F32) cannot be given. Similarly, in panic disorder (ICD-10 F41.0) symptoms must not be due a medical factor in order to meet diagnostic criteria. For a diagnosis of Generalized Anxiety Disorder (GAD), worries have to be disproportionate or unreasonable. In the present study, health-related worries did not count toward a diagnosis of GAD. This might account for the low prevalence rate of GAD in this study (5.6\%) compared with 10\%-15.8\% (Yellowlees et al 1987; Karajgi et al 1990; Aghanwa and Erhabor 2001) found in former studies. The prevalence of GAD found in this sample might thus underestimate the scale of clinically relevant anxiety and worries.
Even if some of the reported symptoms did not meet diagnostic criteria for the above mentioned reasons, they still reflect clinically relevant psychopathology (Rief et al 2005). Such clinically relevant syndromes can be diagnosed according to ICD-10, for example as adjustment disorder, and anxiety or mood disorder due to a general medical condition (Figure 1).

The DSM-IV explicitly mentions COPD for anxiety disorder due to a medical condition (Frances et al 1995) and assumes that anxiety may be a direct result of the chronic hyperventilation pattern or of neurobiologically increased $\mathrm{CO}_{2}$ sensitivity (Dratcu 2000; Mikkelsen et al 2004). Therefore, these diagnoses should be considered more rigorously in future COPD studies. 


\begin{tabular}{ccl}
\hline ICD-10 & $\begin{array}{c}\text { DSM- } \\
\text { IV }\end{array}$ & Diagnosis \\
\hline F43.2 & 309.x & Adjustment disorder \\
F43.20 & 309.0 & - with depressed mood \\
F43.28 & 309.24 & - with anxiety \\
F43.22 & 309.28 & - with mixed depressed mood and anxiety \\
\hline F06.4 & 293.84 & Anxiety disorder due to a general medical condition \\
F06.3x & 293.83 & Mood disorder due to a general medical condition \\
\hline F32.9/F33.9 & 311 & $\begin{array}{l}\text { Depressive disorder not otherwise specified (NOS), within this } \\
\text { category: } \\
\text { - Recurrent brief depressive disorder: depressive episodes } \\
\text { lasting from 2 days up to 2 weeks, occurring at least one a } \\
\text { month for 12 month } \\
\text { - Situations in which the clinician has concluded that a } \\
\text { depressive disorder is present but unable to determine whether } \\
\text { it is primary, due to a general medical condition, or substance } \\
\text { induced. }\end{array}$ \\
\hline
\end{tabular}

Figure I Diagnoses that warrant further consideration.

\section{Intervention}

Psychological disorders in patients should be treated pharmacologically and/or psychologically regardless of whether they are a direct consequence of the disease in the sense of an organic-related psychological disorder, an independent comorbid psychological disorder, or a reactive disorder. However, $70 \%$ of affected COPD patients refuse proposed pharmacological treatments (Yohannes et al 2001). This might be due to the large number of drugs already taken by such patients (on average 6.4, maximum of 17 in the present study).

Psychological interventions are often considered skeptically by patients and pneumologists. Hence it is important to point out the negative effects of increased anxiety or depression on the quality of life of COPD patients.

The high efficacy of cognitive-behavioral approaches in the treatment of anxiety disorders (Mitte 2005) and depression disorders (Maat et al 2007) is beyond doubt. The efficacy of additional psychological interventions in patients with other somatic diseases, such as chronic pain (Hoffman et al 2007) or cancer (Newell et al 2002) has also been demonstrated.
The efficacy of psychological interventions in COPD patients with comorbid anxiety or depressive disorders is yet unclear (Coventry and Gellatly in press). There have only been a few studies with mostly small sample sizes. Two pilot studies (Lisansky and Clough 1996; Eiser et al 1997) reported improved quality of life (Lisansky and Clough 1996) but no reduced levels of anxiety. In a controlled, randomized cognitive-behavioral study, a one-session short-term intervention could significantly reduce anxiousness and depression in COPD patients (Kunik et al 2001). A small randomized controlled trial (RCT) (de Godoy and de Godoy 2003) showed significantly decreased depression and anxiety levels after psychotherapy (including cognitive-behavioral interventions). Cognitive Behavioral Group Therapy (CBT) in COPD patients with clinically significant symptoms of depression and anxiety resulted in a significant improvement of their quality of life (Kunik et al 2008). CBT did not differ from COPD education, however, which also resulted in significant improvements regarding quality of life, anxiety und depression. In both treatment groups, improvements were maintained until follow-up. 
However, it is questionable whether there was sufficient time for individualized CBT interventions when using groups of 10 participants $(8 \times 60$ minutes $)$.

Thus, in addition to the conventional COPD education and comprehensive pulmonary rehabilitations, which are effective in the short term (Coventry and Hind 2007), it is essential to establish appropriate short-term psychological interventions for COPD patients with psychological comorbidity by therapists trained in behavior medicine. Future research should therefore focus on the development and evaluation of effective psychological interventions for COPD patients with psychological comorbidities.

\section{Spouses}

The finding that the spouses' anxiousness is a predictor for the health-related quality of life in patients underscores the importance of involving anxious spouses in intervention programs. Future studies will have to show whether this is a helpful tool to indirectly improve health-related quality of life in patients.

Further investigations and panel studies are needed to analyze the influence of other psychological factors (eg, satisfaction in the relationship, social support/distress, coping or avoidance of physical effort) on the quality of life of COPD patients.

\section{Disclosures}

The authors have no conflicts of interest to declare.

\section{References}

Aghanwa HS, Erhabor GE. 2001. Specific psychiatric morbidity among patients with chronic obstructive pulmonary disease in a Nigerian general hospital. J Psychosom Res, 50:179-83.

Aydin IO, Ulusahin A. 2001. Depression, anxiety comorbidity, and disability in tuberculosis and chronic obstructive pulmonary disease patients: applicability of GHQ-12. Gen Hosp Psychiatry, 23:77-83.

Borak J, Sliwinski P, Piasecki Z, et al. 1991. Psychological status of COPD patients on long term oxygen therapy. Eur Respir J, 4:59-62.

Chavannes NH, Huibers MJH, Schermer TRJ, et al. 2005. Associations of depressive symptoms with gender, body mass index and dyspnea in primary care COPD patients. Fam Pract, 22:604-7.

Coventry, PA, Gellatly, JL. Improving outcomes for COPD patients with mild-to-moderate anxiety and depression: A systematic review of cognitive behavioral therapy. Br J Health Psychol. In press.

Coventry, PA, Hind, D. 2007. Comprehensive pulmonary rehabilitation for anxiety and depression in adults with chronic obstructive pulmonary disease: Systematic review and meta-analysis. J Psychosom Res, 63:551-65.

Crockett AJ, Cranston JM, Moss JR, et al. 2002. The impact of anxiety, depression and living alone in chronic obstructive pulmonary disease. Qual Life Res, 11:309-16.

Cully JA, Graham DP, Stanley MA, et al. 2006. Quality of life in patients with chronic obstructive pulmonary disease and comorbid anxiety or depression. Psychosomatics, 47:312-9.
De Godoy D, de Godoy RF. 2003. A randomized controlled trial of the effect of psychotherapy on anxiety and depression in chronic obstructive pulmonary disease. Arch Phys Med Rehabil, 84:1154-7.

DHS, 2005. Substanzbezogene Störungen im Alter. Ahaus: Lensing Druck.

Di Marco F, Verga M, Reggente M, et al. 2006. Anxiety and depression in COPD patients: The roles of gender and disease severity. Respir Med, 100:1767-74.

Dillmann U, Nilges P, Saille P, et al. 1994. Behinderungseinschätzung bei chronischen Schmerzpatienten (PDI). Schmerz, 8:100-14.

Dratcu L, 2000. Panic, Hyperventilation and perceptuation of anxiety. Prog Neuro-Psychopharmacol Biol Psychiatry, 24:1069-89.

Dyer CAE, Singh SJ, Stockley RA, et al. 2002. The incremental shuttle walking test in elderly people with chronic airflow limitation. Thorax, 57:34-8.

Eiser N, West C, Evans S et al. 1997. Effects of psychotherapy in moderately severe COPD. A pilot study. Eur Respir J, 10:1581-4.

Engström CP, Persson LO, Larsson S, et al. 2001. Health-related quality of life in COPD: why both disease-specific and generic measures should be used. Eur Respir J, 18:69-76.

Felker B, Katon W, Hedrick S, et al. 2001. The association between depressive symptoms and health status in patients with chronic obstructive pulmonary disease. Gen Hosp Psychiatry, 23:56-61.

Frances A, First MB, Pincus HA, 1995. DSM-IV Guidebook. Washington: American Psychiatric Press.

Franke GH, 2000. Symptom-Checkliste von L.R. Derogatis (SCL-90-R). Göttingen: Beltz.

Gudmundsson G, Janson C, Lindberg E, et al. 2005. Risk factors for rehospitalisation in COPD: role of health status, anxiety and depression. Eur Respir J, 26:414-9.

Hiller W, Zaudig M, Mombour W, 1997. ICD-10 Internationale Diagnose Checklisten. Göttingen: Hogrefe and Huber.

Hinz A, Klaiberg A, Brähler E, et al. 2006. Der Lebensqualitätsfragebogen EQ-5D: Modelle und Normwerte für die Allgemeinbevölkerung. Psychother Psych Med, 56:42-8.

Hoffman BM, Papas RK, Chatkoff DK, et al. 2007. Meta-analysis of psychological interventions for chronic low back pain. Health Psychol, 26:1-9.

Hütter BO, 2003. SGRQ - St. Georges Respiratory Questionnaire. In: Schumacher J, Klaiberg A, Brähler E, (eds). Diagnostische Verfahren zu Lebensqualität und Wohlbefinden. Göttingen: Hogrefe. p. 280-5.

Hynninen KMJ, Breitve MH, Wiborg AB, et al. 2005. Psychological characteristics of patients with chronic obstructive pulmonary disease: a review. J Psychosom Res, 59:429-43.

Kanervisto M, Kaistila T, Paavilainen E. 2007. Severe chronic obstructive pulmonary disease in a family's everyday life in Finland: Perceptions of people with chronic obstructive pulmonary disease and their spouses. Nurs Health Sci, 9:40-7.

Kara M, Mirici A. 2004. Loneliness, depression, and social support of Turkish patients with chronic obstructive pulmonary disease and their spouses. J Nurs Scholarsh, 36:331-6.

Karajgi B, Rifkin A, Doddi S, et al. 1990. The prevalence of anxiety disorders in patients with chronic obstructive pulmonary disease. Am J Psychiatry, 147:200-1.

Keele-Card G, Foxall MJ, Barron CR. 1993. Loneliness, depression, and social support of patients with COPD and their spouses. Public Health Nurs, 10:245-51.

Kim FHS, Kunik ME, Molinari V, et al. 2000. Functional impairment in COPD patients. The impact of anxiety and depression. Psychosomatics, 41:465-71.

Kunik ME, Veazey C, Cully, JA, et al. 2008. COPD education and cognitive behavioral therapy group treatment for clinically significant symptoms of depression and anxiety in COPD patients: a randomised controlled trial. Psychol Med, 38:385-96.

Kunik ME, Roundy K, Veazey C, et al. 2005. Surprisingly high prevalence of anxiety and depression in chronic breathing disorders. Chest, 127:1205-11. 
Kunik ME, Braun U, Stanley MA, et al. 2001. One session's cognitive behavioral therapy for elderly patients with chronic obstructive pulmonary disease. Psychol Med, 31:717-23.

Lin M, Chen Y, McDowell I. 2005. Increased risk of depression in COPD patients with higher education and income. Chron Respir Dis, 2:13-9.

Lisansky DP, Clough DH. 1996. A cognitiv-behavioral self-help educational program for patients with COPD : a pilot study. Psychother Psychosom, 65:97-101.

Maat de SM, Dekker J, Schoevers RA, et al. 2007. Relative efficacy of psychotherapy and combined therapy in the treatment of depression: a meta-analysis. Eur Psychiatry, 22:1-8.

Mikkelsen LR, Middelboe T, Pisinger C, et al. 2004. Anxiety and depression in patients with chronic obstructive pulmonary disease (COPD). A review. Nord J Psychiatry, 58:65-70.

Mitte K. 2005. Meta-analysis of the efficacy of psycho- and phamacotherapy in panic disorder with and without agoraphobia. J Affect Disord, $88: 27-45$.

Newell SA, Sanson-Fisher RW, Savolainen NJ. 2002. Systematic review of psychological therapies for cancer patients: overview and recommendations for future research. J Natl Cancer Inst, 94:558-84.

Ng T-P, Niti M, Tan W-C, et al. 2007. Depressive symptoms and chronic obstructive pulmonary disease. Arch Intern Med, 167:60-7.

Pinto RA, Holanda MA, Medeiros MMC, et al. 2007. Assessment of the burden of caregiving for patients with chronic obstructive pulmonary disease. Respir Med, 101:2402-8.

Rief W, Martin A, Klaiberg A, et al. 2005. Specific effects of depression, panic, and somatic symptoms on illness behavior. Psychosom Med, 67:596-601.

Saß H, Wittchen H-U, Zaudig M, 1996. Diagnostisches und statistisches Manual psychischer Störungen DSM-IV. Göttingen: Hogrefe.

Schulenburg Graf von der JM, Claes C, Greiner W, et al. 1998. Die deutsche Version des EuroQOL-Fragebogens. Z f Gesundheitswiss, 6:3-20.
Singh SJ, Morgan MDL, Sciott S, et al. 1992. Development of a shuttle walking test of disability in patients with chronic airways obstruction. Thorax, 47:1019-24.

Stage KB, Middelboe T, Pisinger C. 2003. Measurement of depression in patients with chronic obstructive pulmonary disease (COPD). Nord J Psychiatry, 57:297-301.

Tait RC, Chibnall JT. 2005. Factor structure of the Pain Disability Index in workers' compensation claimants with low back injuries. Arch Phys Med Rehabil, 86:1141-6.

Tait RC, Pollard CA, Margolis RB, et al. 1987. The Pain Disability Index: Psychometric and validity data. Arch Phys Med Rehabil, 68:438-41.

Trollor JN, Anderson TM, Sachdev PS, et al. 2007. Prevalence of mental disorders in the elderly: The Australian National Mental Health and Well-Being-Survey. Am J Geriatr Psychiatry, 15:455-66.

Wernicke TF, Linden M, Gilberg R, et al. 2000. Ranges of psychiatric morbidity in the old and the very old results from the Berlin Aging Study (BASE). Eur Arch Psychiatry Clin Neurosci, 250:111-9.

WHO, 1993. Internationale Klassifikation psychischer Störungen - ICD-10 Kapitel V (F). Bern: Huber.

Yellowlees PM, Alpers JH, Bowden JJ, et al. 1987. Psychiatric morbidity in patients with chronic airflow obstruction. Med J Aust, 146:305-7.

Yohannes AM, Baldwin RC, Connolly K. 2005. Predictors of 1-year mortality in patients discharged from hospital following acute exacerbation of chronic obstructive pulmonary disease. Age Aging, 34:491-6.

Yohannes AM, Baldwin RC, Connolly MJ. 2006. Depression and anxiety in elderly patients with chronic obstructive pulmonary disease. Age Aging, 35:457-9.

Yohannes AM, Connolly MJ, Baldwin RC. 2001. A feasibility study of antidepressant drug therapy in depressed elderly patients with chronic obstructive pulmonary disease. Int J Geriatr Psychiatry, 16:451-4. 